Archives of

Women's

Mental Health

Printed in Austria

Erratum

\title{
Group interpersonal psychotherapy for postnatal depression: a pilot study
}

\section{R. Reay et al.}

In the article "Group interpersonal psychotherapy for postnatal depression: a pilot study" by R. Reay et al. [Arch Womens Ment Health (2006) 9: 31-39; DOI 10.1007/s00737-005-0104-x] unfortunately joint authorship was incomplete. The authors would like to acknowledge Dr. Rajeev Kumar as a co-author in the study.

The complete by-line should read:

R. Reay ${ }^{1}$, Y. Fisher ${ }^{2}$, M. Robertson ${ }^{3}$, E. Adams ${ }^{4}$, C. Owen ${ }^{5}$, and R. Kumar ${ }^{1}$ 